\title{
UV-VIS STUDY ON POLYANILINE DEGRADATION AT DIFFERENT pHS AND THE POTENTIAL APPLICATION FOR ACID-BASE INDICATOR
}

\author{
Said Ali Akbar ${ }^{1, *}$ and Erwinsyah Satria ${ }^{2}$ \\ ${ }^{1}$ Department of Chemical Education, UniversitasSerambiMekkah, 23245, Aceh, Indonesia \\ ${ }^{2}$ Department of Elementary School Teacher Education, Universitas Bung Hatta, 25586, Padang, \\ Indonesia \\ *E-mail: said.aliakbar@serambimekkah.ac.id
}

\begin{abstract}
This study elaborates the effect of $\mathrm{pH}$ on color changes of polyaniline (PAni) that might have application as acidbase indicators. PAni was synthesized by rapidly mixing aniline with ammonium persulfate in deionized water media. The green precipitatewas washed by using $\mathrm{HCl} 1 \mathrm{M}$ and acetone, then the color changed to Emeraldine Base (EB) after the predicate was dissolved in DMSO. The solution was adjusted in various $\mathrm{pH}$ that was $\mathrm{pH} 1-12$ and the color change wasmonitored by UV-vis spectrophotometer. The absorbance of UV-Vis spectra showed dramatically increasing at $650 \mathrm{~nm}$ along with $\mathrm{pH}$ increment that waspH 3-12 (quinoid peak). The solution on the lower $\mathrm{pH}$ shown the higher absorbance at $430 \mathrm{~nm}$ due toconfigure the polaron on the polymer. The EB solution shows the green color at $\mathrm{pH} 1-3$, blue color at $\mathrm{pH} 4-11$, and violet color at $\mathrm{pH} 12$. Therefore, PAni was potentially used as an acid-base indicator.
\end{abstract}

Keywords: Acid-Base, Indicator, pH, Polyaniline, Titration

(C) RASĀYAN. All rights reserved

\section{INTRODUCTION}

Today, with the many instrumentation techniques available for chemical analysis, conventional methods are still considered to be suitable for most applications in various samples. Titrimetry is one of the conventional analytical techniques, where the endpoint of the titration is indicated by indicator substances that were previously added into the analyte solution. The color of change is immediately visible after the equivalence point has been reached. ${ }^{1-3}$

The acid-base indicator is a substance that changes color due to changes in $\mathrm{pH}$. Most indicators are weak organic acids or base dyes that accept or donate electrons. Theconjugate bases or acidsshow different colors due to differences in the absorption spectrum. ${ }^{4,5}$ Usually indicators are pigments or dyes that are isolated from various sources including fungi, minerals, plants, and animals.$^{6-8}$ The colors that arise in plants are caused by naturally occurring organic substances such as flavones, flavonols, xanthine, anthocyanins, azo compounds, etc. Some flavones, flavonols, anthocyanins and other naturally occurring substances are very sensitive to changes in $\mathrm{pH}^{9-10}$ Some natural indicators have been extracted, namely Bougainvillea, Hibiscus (red species), and roses, Ixoracoccinea, Datura stramonium, Helianthus Annuus, Caesalpiniapulcherrima and Ipomoea palmate rail creeper; Neriumodorum extract and Thespesiapopulnea; Morus alba Linn fruit. ${ }^{1}$ Among many conductive polymers such as polyphenylene, vinyl polyphenylene, polypyrrole, polyethylene and polyaniline, many studies have preferred polyaniline (PAni). This is due to the low cost of monomers, ease of synthesis control, unique electrical properties, electrochemical properties, easy polymerization, high environmental stability, and easy mixing with other polymers. ${ }^{13}$ Scientists' attention and interest in the development of research on PAni is increasing, PAni is not only for various applications in microelectronic devices, ${ }^{16}$ such as sensors and actuators, ${ }^{17}$

Rasayan J. Chem., 12(3), 1212-1218(2019)

http://dx.doi.org/10.31788/RJC.2019.1235370

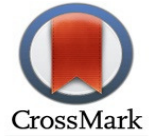


diodes,${ }^{18}$ anti-corrosion layers, ${ }^{19}$ electromagnetic shields, ${ }^{20}$ batteries, ${ }^{13-14}$ and supercapacitor, ${ }^{21}$ but also to explore the mechanism of nanofiber formation, ${ }^{15}$ in applications for other conduction polymers.

PANI consists of three oxidation numbers. Namely, leucoemeraldine, which is a condition that is sufficiently reduced, emeraldine, that is $50 \%$ oxidized, and the form of pernigraniline is fully oxidized. ${ }^{14}$ Emeraldine base (EB) is believed to be the most useful form of polyaniline because of its high stability at room temperature, the fact that after acid doping as a form of emeraldine salt (ES) has high electrical properties. However, leucoemeraldine and pernigraniline are poor conductors, even though they have been doped with acid. ${ }^{13,18}$ The EB form which has a dark blue color can be doped (protonated by acids such as $\mathrm{HCl}$ ) to form ES which shows green; the ES form can also be reduced by alkaline solutions. ${ }^{19}$ PAni's color presence is unusual for our research trying to assess as an acid-base indicator. Therefore, in this paper, we investigate changes in PAni color by Ultraviolet (UV) spectroscopy depending on $\mathrm{pH}$. Then, we submit the potential application as an indicator of acids and bases.

\section{Material}

\section{EXPERIMENTAL}

The aniline monomer (Aldrich, 99.5\%), 37\% hydrochloric acid ( $\mathrm{HCl}$ ), ammonium peroxydisulfate (APS), ammonia $\left(\mathrm{NH}_{3} \cdot \mathrm{H}_{2} \mathrm{O}\right)$, acetone, Aquadest, dimethylsulfoxide (DMSO). Potassium hydrogen phthalate $\left(\mathrm{C}_{8} \mathrm{H}_{5} \mathrm{KO}_{4}\right)$, potassium dihydrogen phosphate $\left(\mathrm{KH}_{2} \mathrm{PO}_{4}\right)$, sodium tetraborate $\left(\mathrm{Na}_{2} \mathrm{~B}_{4} \mathrm{O}_{7}\right)$, sodium hydroxide $(\mathrm{NaOH})$, and sodium bicarbonate $\left(\mathrm{NaHCO}_{3}\right)$.

\section{Synthesis of PANI}

A certain amount of aniline $\left(\rho=1.022 \mathrm{~g} \mathrm{~mL}^{-1}\right)$ and $20 \mathrm{~mL}$ of $1 \mathrm{M} \mathrm{HCl}$ were treated for $30 \mathrm{~min}$ under ultrasonic dispersion. Furthermore, the second solution was prepared from $4.5 \mathrm{~g}$ of APS in $32 \mathrm{~mL}$ deionized water. Then, both solutions were mixed and shaken briefly. The polymerization allowed to take $5^{0} \mathrm{C}$ without stirring for one day (24 hours). The green precipitated known as PAniEmeraldine Salt (ES) was washed using an $\mathrm{HCl} 1 \mathrm{M}$ and acetone. Next, dedoped using $1 M \mathrm{NH}_{4} \mathrm{OH}$ until 3 hours gone to make PAniEmeraldine Base (EB) ${ }^{13}$ The preparation of PAni solution was carried out by dissolved PAniEB in DMSO. Known that PAni in the form of EB has better solubility than in the way of its salt. ${ }^{14}$

\section{Preparation of Solutions at pH 1-12}

The solutions are prepared at a range of $\mathrm{pH} 1-12$. These ranges suppose to monitor the color change in the PAni solution. For $\mathrm{pH}$ 1-2 solution, it was adjusted by adding $\mathrm{HCl}$ solution. Then, the buffer solution with $\mathrm{pH}$ 3-5 was prepared by dissolving 10,21 g potassium hydrogen phthalate in $0.1 \mathrm{M} \mathrm{HCl}$ with appropriate volume. Next, $\mathrm{pH}$ 6-8 was are made by mixing $6.81 \mathrm{~g}$ of potassium dihydrogen phosphate and adjusted with addition $0.1 \mathrm{M} \mathrm{NaOH}$ solution. Then, $\mathrm{pH} 9-10$ of buffer solution, was composed of $4.77 \mathrm{~g}$ sodium tetraborate that was dissolved into $0.1 \mathrm{M}$ HCland the $\mathrm{pH}$ was adjusted $\mathrm{pH}$ 9, and other with $0.1 \mathrm{M} \mathrm{NaOH}$ to prepare $\mathrm{pH} 10$ and 12 buffer solution.

\section{Ultraviolet (UV) Spectroscopy Detection}

The spectrophotometer of the Thermo Scientific Evolution 220 Series was used to quantify the sample. DMSO was used to calibrate the instrument. Furthermore, $0.1 \mathrm{~mL}$ of each sample diluted with $10 \mathrm{~mL}$ of DMSO and $1 \mathrm{~mL}$ of the sample was transferred into the cuvet. The absorbance of the extract was determined within the visible region at 300-900 $\mathrm{nm}$.

\section{Performance of Natural Acid-Base}

Titrations were carried outby using $0.1 \mathrm{M} \mathrm{H}_{2} \mathrm{SO}_{4}$ and $0.1 \mathrm{M} \mathrm{NaOHfor} \mathrm{strong} \mathrm{acid-strong} \mathrm{base} \mathrm{titration.}$ Then, $0.1 \mathrm{M}$ solution of $\mathrm{CH}_{3} \mathrm{COOH}$ and $0.1 \mathrm{M} \mathrm{NaOH}$ were used for weak acid-strong base titration. The precision and reliability of the endpoint for all experimental samples and trials were repeated three (3) times. The performance of the indicator is also determined by testing samples such as soap, lime, vinegar, and toilet cleaners.

\section{Synthesis of PAni}

\section{RESULTS AND DISCUSSION}

This study adopted the rapidly mixed method for synthesis of conducted PAni in acidic-aqueous media. Aniline solution and APS oxidation solution was mixed at once and quickly. Then, synthesis was carried 
out at $5^{0} \mathrm{C}$ due to the polymerization process of aniline is an exothermic reaction, a cold medium is preferable. ${ }^{16}$ This method has several advantages compared to otherssince it can be done at a large scale to prepare green powder PAni-ES that was easily separated..$^{21}$ Furthermore, PAni-ES residue was dedoped by using ammonium base to obtain PAni-EB.
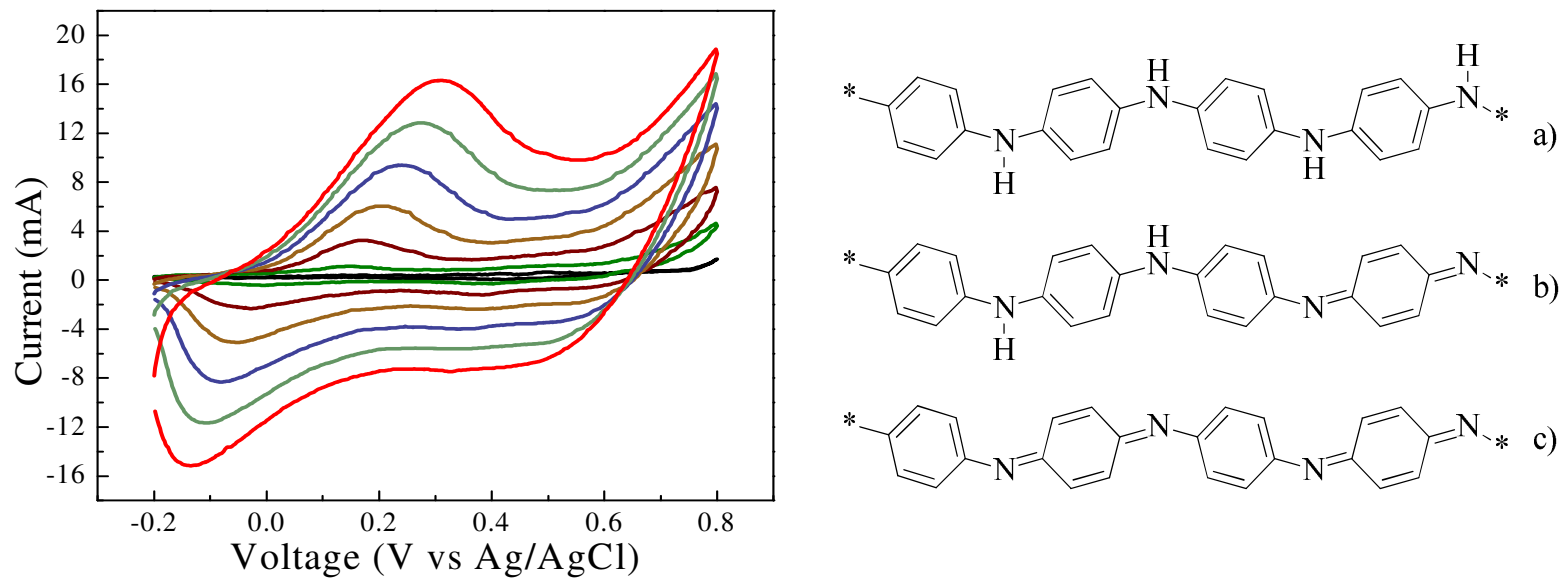

Fig.-1: Cyclic Voltammograms of PANI Film with Different Oxidation State (a) Fully Reduced (b) Half Oxidized

\section{PAni's Material Characterization}

(c) Fully Oxidized

PAnigave unique structures and was characterized based on the oxidation state (i.e., the amine ratio to the imine), and the level of protonation. The polymer oxidation state increases with the quinoid form value (Fig.-1). The three oxidation states found in PAniwere the fully oxidized pernigraniline base (PNB) (Fig.1a), the leucoemeraldine base which was completely reduced (LEB) (Fig.-1b), and half oxidized namely Emeraldine Base (EB) (Fig.-1c).The profile of aniline electrodeposition was studied using cyclic voltammetry (CV) (Fig.-1). This process recorded at sweep rate $50 \mathrm{mV} / \mathrm{s}$ in $1 \mathrm{M} \mathrm{HCl}$ aqueous solution. There are three redox pairs, with oxidation peaks at $0.25 \mathrm{~V}, 0.61 \mathrm{~V}$ (at 4 cycles) and $0.74 \mathrm{~V}$ with $\mathrm{Ag} / \mathrm{AgCl}$ in saturated $\mathrm{KCl}$ solution. The redox process between leucoemeraldine and emeraldine assigned at the anodic peak (Ap) $0.25 \mathrm{~V}$ and the cathodic peak (Cp) $-0.08 \mathrm{~V}$. Additionally, at Ap $0.74 \mathrm{~V}$ and $\mathrm{Cp} 0.58 \mathrm{~V}$ should correspond with the redox betweenemeraldine and pernigraniline, ${ }^{22}$ but the peak is not formed, it is possible the occurrence of redox competitive with the oxidation of water. In the early cycle of the voltammetric process, a small peak appeared on Ap $0.61 \mathrm{~V}$ and $\mathrm{Cp} 0.51 \mathrm{~V}$. This was confirmed as a redox of phenazine formation. This peak was lost during the cycle increases. The creation of phenazine can be through 2 types of reaction. ${ }^{22}$ One of a kind the formation of phenazine was taken place through a redox reaction. On the anode surface, there will be many radical aniline cations. In this case, it allowed the formation of phenazine like this.

In the form of $\mathrm{EB}$, the amount of $-\mathrm{N}-$ with $=\mathrm{N}$ - is the same, so the structure is only found in one quinoid ring. The UV spectra of the EB sequence consist of two common peaks. ${ }^{14}$ Figure 2 shows the first peak at $\sim 630 \mathrm{~nm}$ (quinoid peak) assigned to electron excitation from the benzenoid ring (B) to the quinoid ring (Q) $\left(\pi \mathrm{b} \rightarrow \pi \mathrm{q}^{*}\right)$ [17]. In contrast to ES, the formation of new energy levels caused by the formation of polaron appears at $\sim 451 \mathrm{~nm}$ which indicates the excitation of nonbonding (polaron) electrons to $\pi \mathrm{b}^{*}$. In this way, the UV spectrum of ES displays a lower intensity than the EB form because the ES form caused by the transition from polaron $\rightarrow \pi \mathrm{b}^{*}$ is more leisurely than $\pi_{\mathrm{b}} \rightarrow \pi_{\mathrm{q}}{ }^{*}$ [20]. The second peak in the EB form that appears at $\sim 330 \mathrm{~nm}$ (benzenoid peak) shows the transition $\pi b \rightarrow b^{*}$ associated with $\pi$ electrons in the benzene ring; this peak is still related to the electron transition in the ES form. Because this transition is primarily a function of intra-chain interaction; ${ }^{13}$ The peak at $968 \mathrm{~nm}$ can only be observed in the ES form which is related to the transition of $\pi \mathrm{b} \rightarrow$ polaron.

\section{The pH Effect Of PANI EB Solution}

The solution of EB in DMSO solvent was prepared in 12 vial bottle with $20 \mathrm{~mL}$ volume. Hereafter, the solution $\mathrm{pH}$ 1-12 dropped with same quantity into each bottle, then the transition of EB was monitored with color change and investigated the solution properties by UV-vis spectroscopy. 


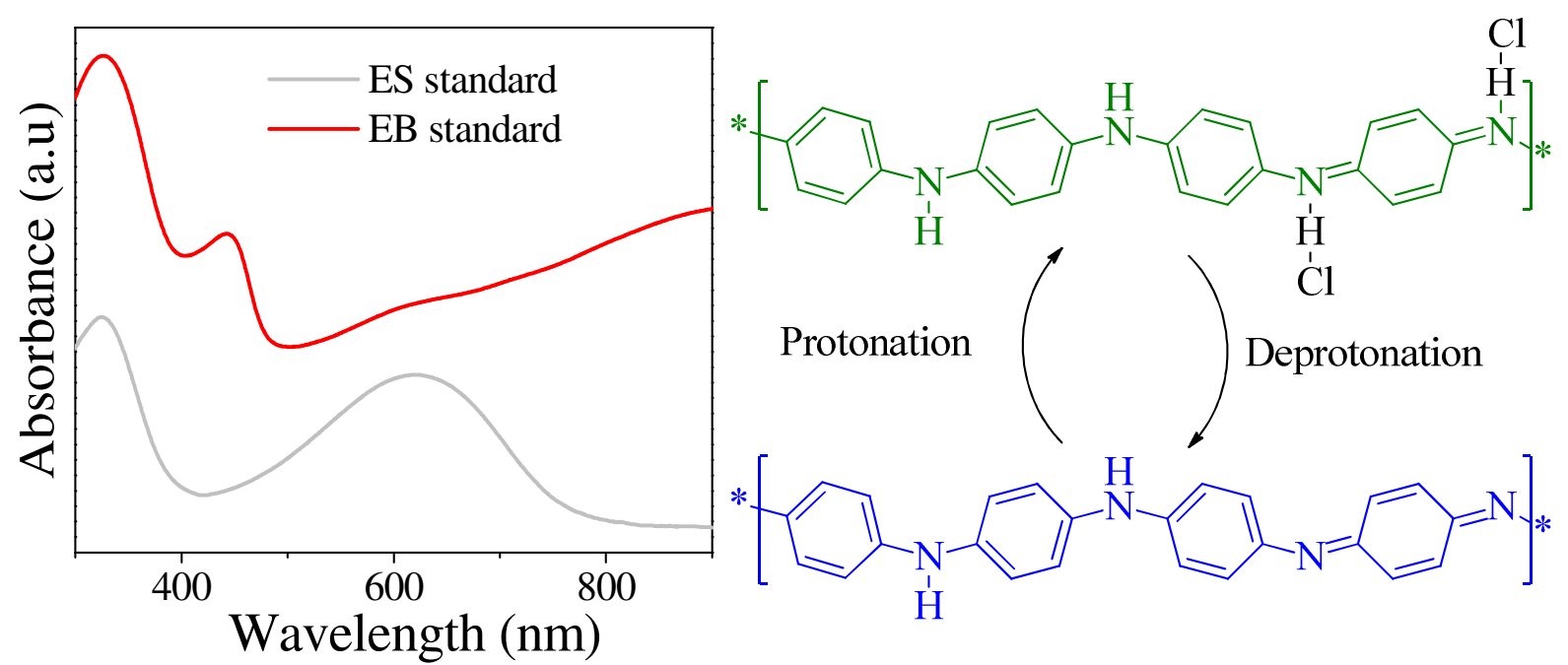

Fig.-2: Visible Spectra of PAni Synthesis in DMSO Solvent and its Mechanism of Protonation

When added the acid solution at $\mathrm{pH} 1$ produced a green color as indicated in Figure 3 . As increasing $\mathrm{pH} 2$ to 4, following with degrading the color of the EB solution from green to blue. The UV-Vis absorbance increased at $650 \mathrm{~nm}$ along with enhancement of $\mathrm{pH} 3-4$. This phenomenon exhibited the EB solution still formed at $\mathrm{pH}$ 3-4.

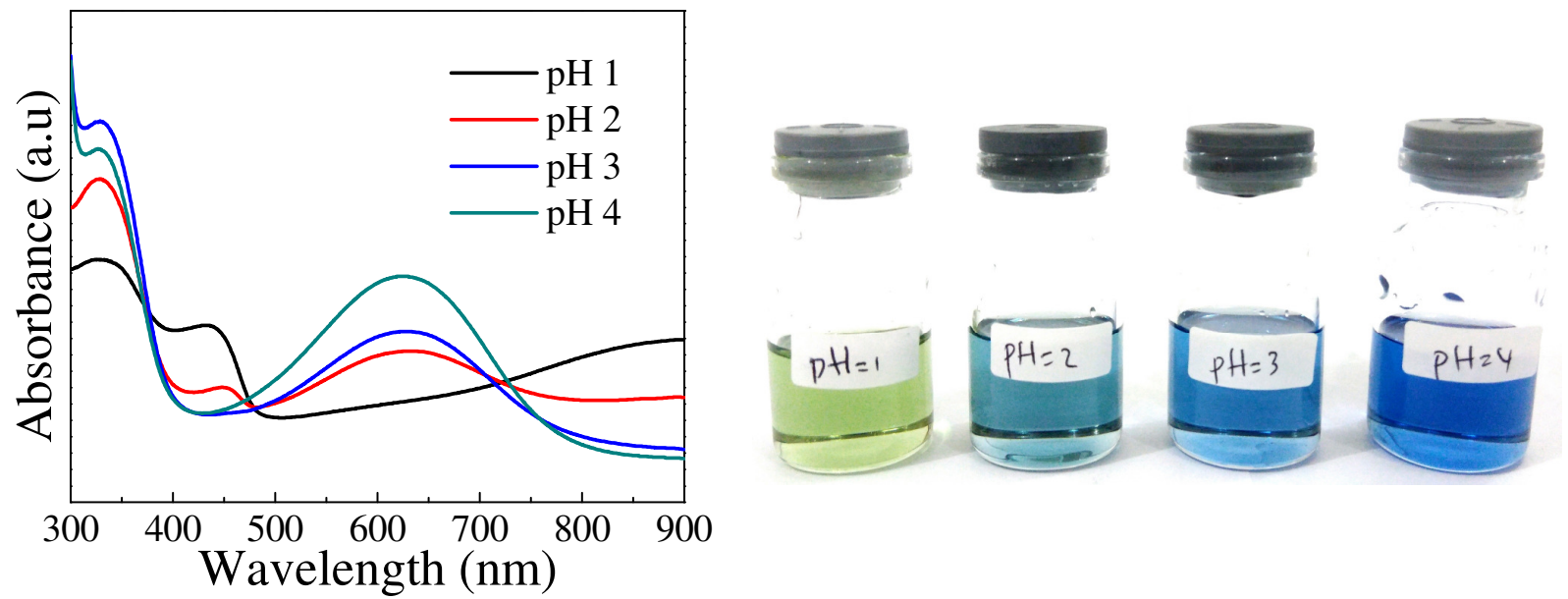

Fig.-3: Visible Spectra of PANI Solution at pH 1-4 and it's Color Change

Meanwhile, It should also be noted that PANI is not completely transformed to the ES form at pH 2 because a minor fraction of the EB form can still be observed at $650 \mathrm{~nm}$ in the spectrum. In another hand, the character of the ES form was displayed with increasing absorbance at $\sim 430 \mathrm{~nm}$. The solution on the lower $\mathrm{pH}$, with more $\mathrm{H}^{+}$source, could conveniently configurate the polaron that corresponds the higher absorbance at band transitions approximately 430 and $>/ 800 \mathrm{~nm}^{14}$

Whereas, the EB solution wasn't indicated the change of color anything at pH 5 - 8 (Fig.-4) except at a neutral solution. This issue could be described by the insoluble PANI in water, ${ }^{14}$ In a neutral solution, no acid-base component affected the EB structure. So, the minor peaks observed in the UV-/vis spectra are interferences caused by the spectrophotometer measuring completely dissolved EB in water. The absorbance maximum of the EB form at $650 \mathrm{~nm}$ has been attributed to the solution at $\mathrm{pH} 8$. All settlement represented the same color at $\mathrm{pH} 5-8$. Similar at $\mathrm{pH} 5-8$, the absorbance of all EB solution at $\mathrm{pH} 9-12$ displayed EB form completely (see Fig.-5). Then, the different color occurred only on the solution at $\mathrm{pH}$ 12 with looking dark blue (violet). 


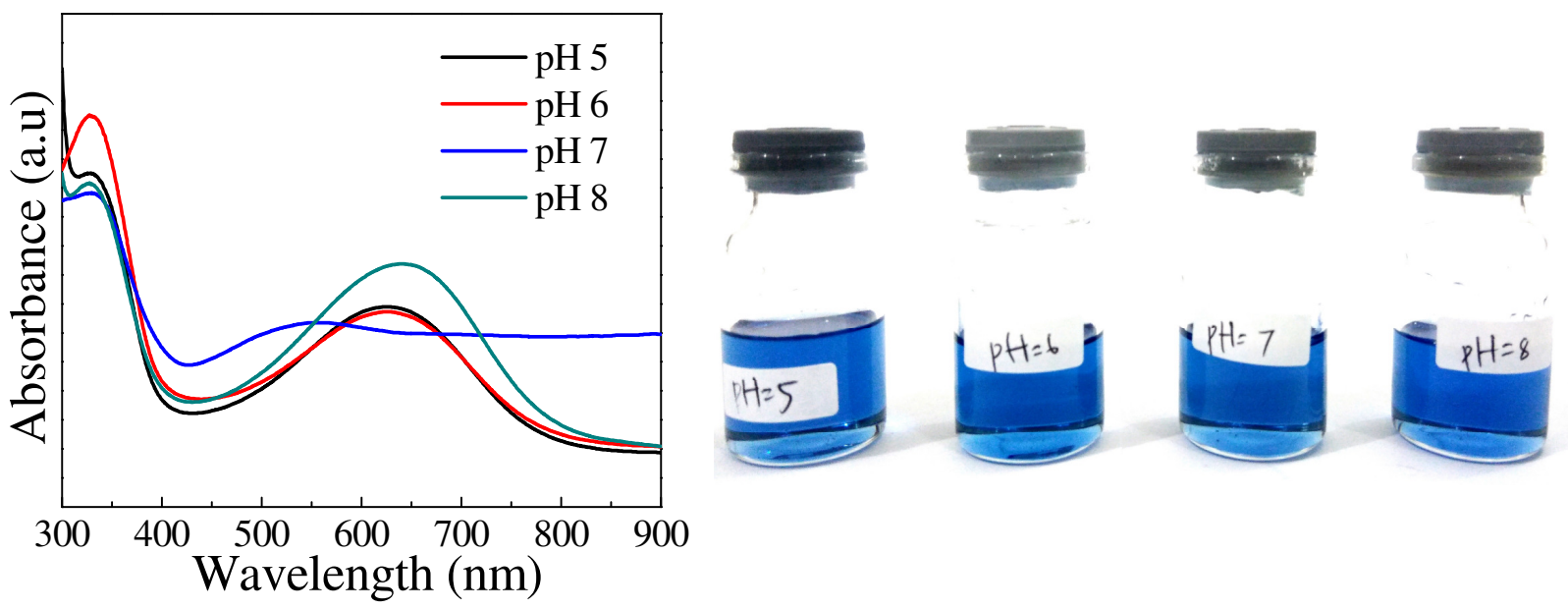

Fig.-4: Visible spectra of PANI Solution at pH 5-8 and its Color Change

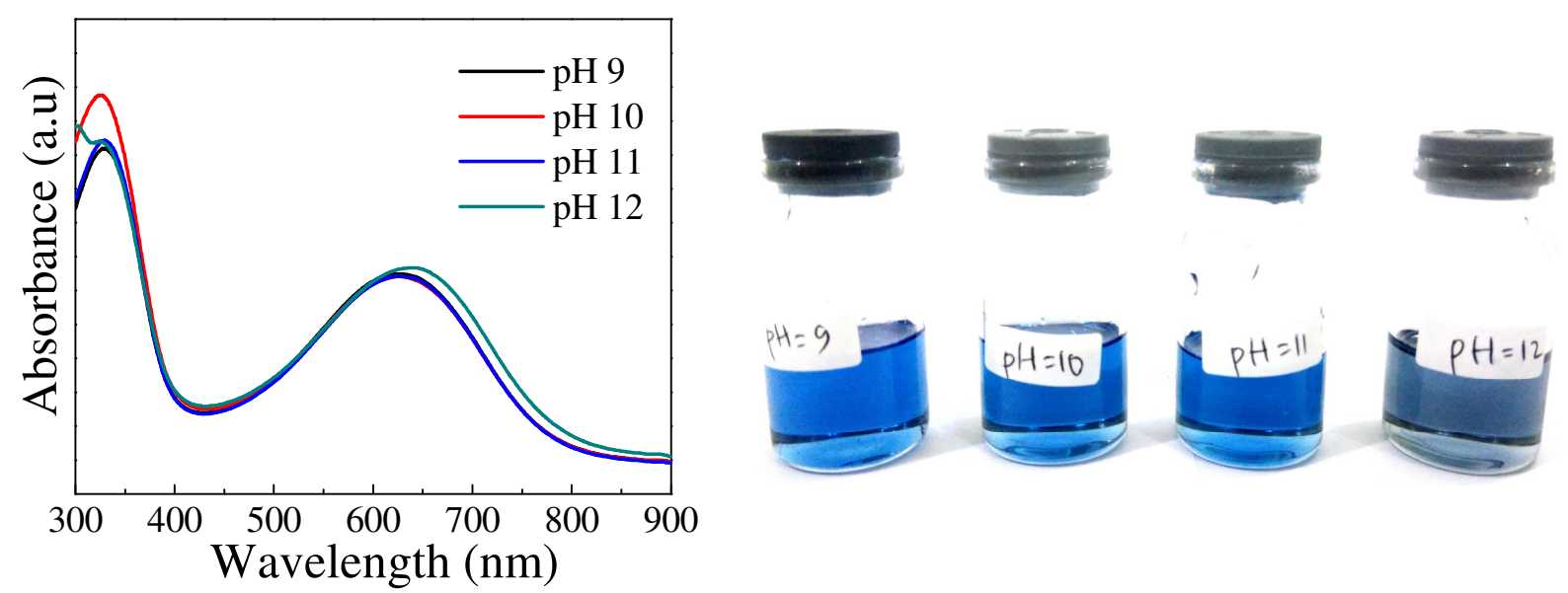

Fig.-5: Visible Spectra of PANI Solution at pH 9-12 and it's Color Change

The ratio of the intensity of the peak quinoid to the benzenoid peak is proportional to the ratio of the quinoid unit to the benzenoid group in PAni. The values reported for the quinoid to benzenoid ratio, in the UV-VIS spectrum of the EB solution are $0.86 \pm 0.05 .{ }^{18,20}$ When the EB form decreases towards LEB, the quinoid to benzenoid ratio values are close to 0.69 , which is where the peak of quinoid changes was slowly shifting from 634 to $645 \mathrm{~nm}$ in the initial stage, and the benzenoid peak also changes gradually towards redshift from 335 to $347 \mathrm{~nm}$. Conversely, when the EB is oxidized to PNB, the quinoid to benzenoid ratio again decreases to 0.69 , but after that, it remains constant at $\sim 0.69$; while the quinoid peak changes slowly blue shifts from $634-571 \mathrm{~nm}$, the benzenoid peak remains at $\sim 335 \mathrm{~nm} .^{14,17,21}$ Therefore, we were able to identify the PAni oxidation state from changes in the quinoid/benzenoid ratio and the shift of the quinoid or benzenoid peak in the UV-vis spectrum. However, all observations at $\mathrm{pH}$ increased from 1 to 12 ; there was no redox reaction seen in the polymer.

\section{Acid-Base Titration with PANI as Indicator}

The application of acid-base titration using the EB indicator has been applied and is presented in Table- 2 . This experiment also uses several standard indicators such as Phenolphthalein (PP) and methyl red (MR), as a comparison. In titrating $10 \mathrm{~mL}$ of $0.1 \mathrm{M} \mathrm{NaOH}$ solution using $0.1 \mathrm{M} \mathrm{HCl}$ solution, an apparent color change from pink became colorless using the Phenolphthalein (PP) indicator, the color loss was observed when the $\mathrm{pH}$ had dropped past 8.00. Furthermore, in the red methyl color changes from yellow to orange when the $\mathrm{pH}$ has become 5.26 and becomes very bright red when the $\mathrm{pH}$ has passed 4.00. The use of EB observed violet color when $\mathrm{HCl}$ has not yet been added, the color change appears to turn blue between the $\mathrm{pH}$ range 7-4 slowly and becomes green when the $\mathrm{pH}$ has passed 3 towards 1. 
Similar results are also shown in the titration of $10 \mathrm{~mL}$ of $0.1 \mathrm{M} \mathrm{CH}_{3} \mathrm{COOH}$ solution with $0.1 \mathrm{M} \mathrm{NaOH}$ solution. The use of the EB indicator shows green changes to blue when $\mathrm{pH}$ has entered the value of 4 and above, adding further $\mathrm{NaOH}$ after the endpoint of the titration indicates the violet color on the indicator. Therefore, the EB indicator has the potential to be used as an excellent acid-base indicator, because it can work in acidic and basic regions.

\begin{tabular}{|c|c|c|c|c|}
\hline \multicolumn{2}{|c|}{ Titration } & & & \\
\hline Titrant & Titrand & Indicator & Color & $\mathrm{pH}$ \\
\hline $\mathrm{HCl}$ & $\mathrm{NaOH}$ & $\begin{array}{c}\text { Phenolphthalein } \\
\text { Methyl Red } \\
\text { EB } \\
\text { EB } \\
\end{array}$ & $\begin{array}{l}\text { Pink to colorless } \\
\text { Yellow to pink } \\
\text { Violet to blue } \\
\text { Violet to Green } \\
\end{array}$ & $\begin{array}{r}12.02-5.77 \\
12.12-5.26 \\
12.52-10.34 \\
12.20-3.02 \\
\end{array}$ \\
\hline $\mathrm{NaOH}$ & $\mathrm{CH}_{3} \mathrm{COOH}$ & $\begin{array}{c}\text { Phenolphthalein } \\
\text { Methyl Red } \\
\text { EB } \\
\text { EB }\end{array}$ & $\begin{array}{l}\text { Colorless to pink } \\
\text { Light Red to yellow } \\
\text { Green to Blue } \\
\text { Green to Violet }\end{array}$ & $\begin{array}{c}2.95-9.37 \\
3.02-8.85 \\
2.92-8.95 \\
2.97-12.02\end{array}$ \\
\hline
\end{tabular}

\section{Performance of PANI with natural Acid-Base}

The potential as an indicator shown by the EB is also applied directly to natural acid bases. In this section, essential acids are taken from bottle vinegar and lime sold in the market. But for natural cores taken from soda which is sold in building equipment stores, as well as bath soap sold in the market. As shown in Fig.-6, the color change demonstrated in the acid solution tends to be green. Using lime (Fig.-6a), a green color that tends to be cloudy with colloids, this is influenced by other chemical components in lime beside citric acid which affects the overall color change, but ideally, the colors seen towards green. Similar colors are shown in the use of vinegar (Fig.-6b), which is a green solution. Using the natural base of bath soap shows a profound blue color change from the color of the standard indicator solution. As well as showing violet color on the addition of a solution of soda. The entire natural acid-base shows a significant color change. Therefore the use of EB as an acid-base indicator is very potent.

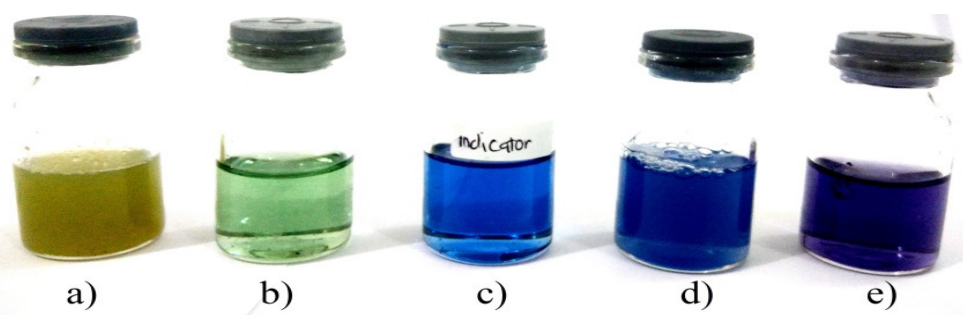

Fig.-6: Colour Change of (c) Indicator PANI Solution by adding (a) Lime (b) Vinegar (d) Soap and (e) Caustic Soda

\section{CONCLUSION}

PAni was synthesized by rapidly mixing of aniline with ammonium persulfate in deionized water media.PAni solution was carried out by dissolved PAni EB in DMSO due to in EB form has better solubility than salt form.The UV-Vis spectra showed dramatically increasing absorbance at $650 \mathrm{~nm}$ along $\mathrm{pH}$ 3-12 (quinoid peak). The solution on the lower $\mathrm{pH}$, with more $\mathrm{H}^{+}$source, conveniently configure the polaron that corresponds the higher absorbance at band transitions approximately $\sim 430$ and $>/ 800 \mathrm{~nm}$. The EB solution shows the green color at $\mathrm{pH} \mathrm{1-3,} \mathrm{blue} \mathrm{color} \mathrm{at} \mathrm{pH} \mathrm{4-11,} \mathrm{and} \mathrm{violet} \mathrm{color} \mathrm{at} \mathrm{pH} 12$. The EB Solution was also applied directly to natural acid bases that displayed the same color change with the pH 1-12 control. Therefore, PAni was potentially used as an acid-base indicator.

\section{ACKNOWLEDGMENT}

This work was promoted by LPPM UniversitasSerambiMekkah. Thanks a lot for this financial support in this research.

REFERENCES

1. M.E. Soltan andS.M.Sirry, J. Chin. Chem. Soc,49, 63(2013), DOI:10.1002/jccs.200200011 
2. E.A.Reshetnyak, V.M.Ostrovskaya, K.V. Goloviznina andN.N.Kamneva, J. Mol. Liq, 248, 610(2017),DOI:10.1016/j.molliq.2017.10.019

3. M.S.Zoromba, Spectrochim. Acta. A, 187, 61(2017),DOI:10.1016/j.saa.2017.06.028

4. A.Sukhanov, A.Ovsyannikova, N.Gavrilenko,N.Saranchina, Procedia. Eng, 168, 477(2016),DOI:10.1016/j.proeng.2016.11.134

5. N.O.M.P.Petrossyan, V.S.Farafonov andA.V. Lebed, J. Mol. Liq, 264, 683(2018),DOI:10.1016/j.molliq.2018.05.076

6. Y.Xiong, K.Pei, Y. Wu andY.Xiong, Food Control, 78, 317(2018), DOI:10.1016/j.foodcont.2017.03.002

7. N.N.Kamneva, V.V.Tkachenko, N.O.M.Petrossyan, A.I.Marynin, A.I. Ukrainets, M.L.Malysheva andE.Osawa, Surf. Eng. Appl. Electrochem, 54, 64(2018),DOI:10.3103/S1068375518010088

8. P.Serra-Mora, Y.Moliner-Martínez, R.J.Herráez-Hernández, Verdú-Andrés and P. Campíns-Falcó, Food. Anal. Methods, 9, 1150(2016), DOI: 10.1007/s12161-015-0294-4

9. D.L.P.Macuvele, G.Z.S.Sithole, K. Cesca, S.L.P.Macuvele andJ.V. Matsinhe, Environ. Sci. Pollut. Res, 23, 11639(2016), DOI: 10.1007/s11356-016-6284-2

10. H.Kahlert, G. Meyer andA.Albrecht, ChemTexts, 2, 7(2016), DOI: 10.1007/s40828-016-0026-4

11. M.Y.Udugala-Ganehenege, N.M.Dissanayake andA.M.K.S.P. Adhikari, J. Inorg. Organomet. Polym, 25, 964(2015),DOI: 10.1007/s10904-015-0200-y

12. B.P.Baldigo, M.A.Kulp andJ.S.Schwartz, Ecol. Indic, $\quad \mathbf{8 8 ,}$ 465(2018),DOI:10.1016/j.ecolind.2018.01.021

13. A. Rochliadi, S.A. Akbar and V. Suendo. In Proceedings of the Joint International Conference on ElectricVehicular Technology and Industrial, Mechanical, Electrical and Chemical Engineering $\begin{array}{lllll}\text { (ICEVT \& } & \text { IMECE), } & \text { Surakarta, } & \text { Indonesia, } & \text { pp. }\end{array}$ (2015),DOI:10.1109/ICEVTIMECE.2015.7496686

14. S.A.Akbar, A.Rochliadi, V.Suendo, N.Saidi, Lelifajri andA.Mardhiah, Rasayan J. Chem, 11, 1525(2018),DOI: 10.31788/RJC.2018.1144064

15. H.Sharifi, S.Majid, Zabihzadeh andM. Ghorbani, CarbohydrPolym, 194, 384(2018),DOI: 10.1016/j.carbpol.2018.04.083

16. J.Li, L.Liu, D.Zhang, D.Yang, J.Guo andJ.Wei, Synth. Met., 192, 15(2014),DOI: 10.1016/j.synthmet.2014.02.026

17. L.Tiggemanna, S.Ballena, C.Bocalona, A.M.Graboskia, A.Manzolib, P. Herrmannb, J.Steffensa, E.Valdugaa andC.Steffensa, J. Food Eng, 180, 16(2016),DOI: 10.1016/j.jfoodeng.2016.02.006

18. S.Ameen, M.S.Akhtar andH.S. Shin, Electrochim. Acta, 215, 200(2016),DOI: 10.1016/j.electacta.2016.08.066

19. Z.Li, J.Hu, Y.Li andJ.Liu, React FunctPolym, 131, 22(2018),DOI: 10.1016/j.reactfunctpolym.2018.07.002

20. P.Gairola, S.P.Gairola, V.Kumar, K.Singh andS.K.Dhawan, Synth. Met, 221, 326(2016),DOI: 10.1016/j.synthmet.2016.09.023

21. A.Eftekhari, L. Li andY. Yang, J. Power Sources, 347, 86(2017), DOI: 10.1016/j.jpowsour.2017.02.054

[RJC-5370/2019] 